\title{
Taxonomic aggregation and redundancy in a tropical macroinfaunal assemblage of the southern Caribbean in the detection of temporal patterns*
}

\author{
ANGELA INÉS GUZMÁN-ALVIS ${ }^{1,2}$ and FRANKLIN CARRASCO² \\ ${ }^{1}$ Instituto de Investigaciones Marinas y Costeras, INVEMAR, Apartado Aéreo 1016, Santa Marta, Colombia. \\ E-mail: aguzman@invemar.org.co \\ ${ }^{2}$ Departamento de Oceanografía, Universidad de Concepción, Casilla 160-C, Concepción, Chile.
}

\begin{abstract}
SUMMARY: The infaunal soft bottom communities of the southern Caribbean are poorly known, partially due to the scarcity of specialised literature and taxonomic expertise for this region. These assemblages might have structurally redundant genera, so it would be possible to study groups of organisms that present a similar pattern to that of the total community. This redundancy can be reflected at higher taxonomic levels. The abundance of the sublittoral infauna of the southern Caribbean was used in multivariate statistical techniques to describe a temporal pattern. This temporal pattern was related to other patterns obtained from a series of genera subsets that were extracted from the total community. These subsets display close relationships (redundancy). Moreover, the total temporal pattern was compared with those obtained from the emphasis of different taxa and by aggregating their abundances at higher taxonomic levels. There is a high structural redundancy that comprises several groups of characteristic, common and dominant genera. Therefore, by emphasising the contributions of common or combinations of common and intermediate taxa, the family level identification appeared to be a good choice to describe the temporal pattern in this region. These results are useful for temporal pattern descriptions of those assemblages in which a high taxonomic uncertainty exists.
\end{abstract}

Key words: tropical macroinfauna, taxonomic resolution, taxonomic redundancy, temporal pattern.

RESUMEN: AGREGACIÓN Y REDUNDANCIA TAXONÓMICA EN LA DETECCIÓN DE PATRONES TEMPORALES EN UNA ASOCIACIÓN MACROINFAUNAL TROPICAL DEL CARIBE SUR. - Las comunidades infaunales de fondos blandos del Caribe sur son pobremente conocidas debido en parte a la escasez de literatura especializada y experiencia taxonómica. Estas asociaciones pueden tener géneros estructuralmente redundantes, podría ser posible estudiar grupos de organismos que conserven los mismos patrones de respuesta a la del total de la comunidad. Esta redundancia se reflejaría en niveles taxonómicos altos. En el Caribe sur la abundancia de la infauna sublitoral se usó en escalamientos multivariados para describir el patrón temporal. Éste se relacionó con los patrones obtenidos a partir de series de subconjuntos de géneros extraídos de la comunidad total y que presentaban altas relaciones con ella (redundancia). Además, el patrón temporal general se comparó con los obtenidos al resaltar diferentes taxa y agregar sus abundancias a niveles taxonómicos altos. Existe una alta redundancia estructural conformada por varios grupos de géneros que caracterizaron la comunidad, que fueron comunes y dominantes. Por lo que, resaltando las contribuciones de los taxa comunes e intermedios, el nivel de identificación a familia es una buena elección para describir los patrones temporales comunitarios en esta región. Estos resultados son útiles para la descripción de patrones temporales en estas asociaciones donde existe una alta incertidumbre taxonómica.

Palabras clave: macroinfauna tropical, redundancia taxonómica, patrones temporales. 


\section{INTRODUCTION}

The redundancy hypothesis proposes that certain species are able to expand their roles in the ecosystem to compensate for those species that are becoming extinct (Walker, 1992). In some communities, certain species are redundant, i.e. they could disappear with little effect on the structure and functioning of the whole community (Snelgrove et al., 1997; Bolger, 2001). It is likely that all the species are not essential for the ecosystem to function; however, this suggestion must be considered with caution since there are linkages between species that are poorly understood, and the removal of one species could affect the support of the ecosystem through the disruption of others (Snelgrove et al., 1997). Increase in diversity enhances the reliability of the ecosystem; an increase in the number of redundant species per functional group increases the reliability of the functioning of the ecosystem (Hanski, 1997; Naeem and Li, 1997; McGrady-Steed et al., 1997).

The concept of structural redundancy in the composition of the community suggests that there must be a considerable redundancy in the species that characterise the community (Clarke and Warwick, 1998; Bolger, 2001). This idea can be used to analyse the community data at higher taxonomic levels than species (Clarke and Warwick, 2001).

Identification to species, or lowest possible taxon, is common practice in the ecological study of communities. Species-level identification, however, may not always be necessary in applied studies such as pollution assessment and monitoring (Ferraro and Cole, 1990). Identifying organisms to the taxonomic level necessary and sufficient to meet the objectives of a study has been called 'taxonomic sufficiency' (Ellis, 1985). As taxonomic sufficiency moves to progressively higher taxa, costs, in terms of the expertise and time needed to identify organism, decrease (Ferraro and Cole, 1990). Taxonomic sufficiency is a pragmatic construct in which the accuracy of identification is balanced against the need for information (Ellis, 1985).

Although identification of organisms to species used to be the norm, several authors have shown that polluted and non-impacted soft bottom assemblages can be discriminated at higher taxonomic levels (Warwick, 1988; Ferraro and Cole, 1990; Warwick et al., 1990; Sommerfield and Clarke, 1995; Vanderklift et al., 1996; Olsgard et al., 1997, 1998). The same results have been noted for similar tropical environments, i.e. a pollution gradient (Agard et al.,
1993). However, the effect of the reduction in taxonomic resolution has not been widely studied with regard to spatial and temporal patterns in tropical infaunal macrobenthic assemblages.

In the tropics, surveys of soft bottom infaunal benthic communities are scarce (Olsgard et al., 1998; Gray, 2002) and the southern Caribbean is not an exception. A possible reason is poor taxonomic knowledge of infauna, especially of more abundant groups, such as polychaetes and peracarid crustaceans. An alternative to overcome this problem is to analyse the samples to taxonomic levels such as the family, if the results from identifications to higher taxonomic levels are comparable to those of species level analysis (Olsgard et al., 1997, 1998; Clarke and Warwick, 2001).

In previous southern Caribbean studies, it has been found that on a spatial scale with depth variations, the aggregation from genus to phylum had no effect, maintaining the same spatial pattern throughout the taxonomic aggregation (Guzmán and García, 1996). If this is the general pattern of shallow bottoms in these areas, then the evaluations could be performed faster, without having to identify specimens to species level. However, in order to examine the general pattern and be able to give recommendations for future investigations, it is necessary to do further studies of faunal patterns at different taxonomic levels.

The purpose of this study is to determine the structural redundancy in the temporal patterns of some infaunal assemblages found in the southern Caribbean using multivariate statistical techniques to analyse the effect of taxonomic aggregation on the temporal patterns.

\section{MATERIALS AND METHODS}

Sampling was conducted at nine stations that were visited three times during 1994-1996 and once in 2001 and in 2002 (Fig. 1). At each station three sediment samples were taken with a van Veen grab $\left(0.05 \mathrm{~m}^{2}\right)$. Samples were sieved through a $0.5 \mathrm{~mm}$ mesh geological screen. The organisms were counted and identified to the genus level because the species-level taxonomy of the southern Caribbean infauna is poorly known whereas-with some exceptions - infauna genera are better defined and robust. The temporal patterns were explored with non-metric multidimensional scaling (NMDS) analysis using the PRIMER software package 


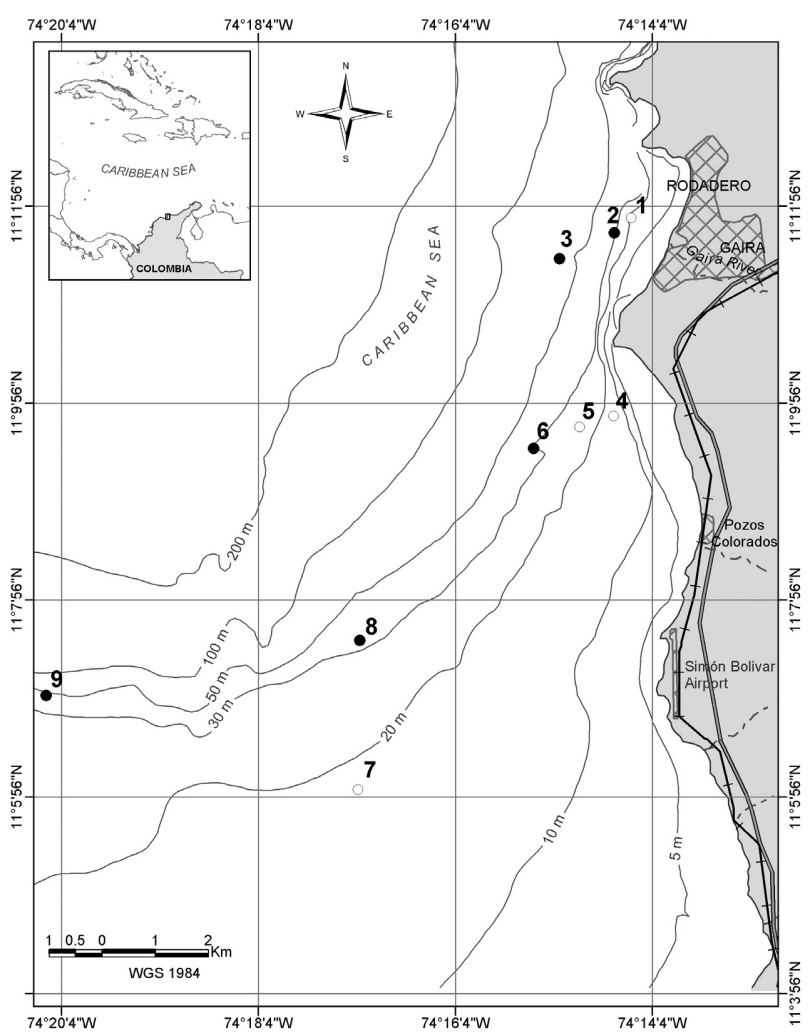

FIG. 1. - Geographic location of nine sites sampled on the shallow continental shelf off Colombian's Caribbean coast. o: Shallow stations; $\bullet$ : deep stations.

(Clarke and Warwick, 2001). The temporal pattern observed for the deep stations compared to that of the shallow stations was very similar. Therefore, the average abundance for all the nine stations was calculated and used for the analysis. No seasonal differences were observed.

\section{Taxonomic redundancy}

Several genera subsets were selected from the Bray-Curtis similarity matrices that were highly correlated (rho $\geq 0.95$ ) with the total genera or fixed matrix (Clarke and Warwick, 1998). Selection was made with the PRIMER v5 'stepwise' algorithm, choosing the $\log (\mathrm{x}+1)$ transformation as indicated below. A stepwise algorithm is a sequential search and involves both forward selection and backward elimination phases. At each iterative stage, a selection is made of the genus which maximally increases the Spearman rank correlation coefficient, and this is added to the existing subset. There is also an elimination step in which the effect of dropping one genus at a time is considered (Clarke and Warwick, 2001). Additionally, genera subsets formed only by polychaetes, crustaceans, molluscs or echinoderms were extracted.
The characteristic, frequent and rare genera were identified in each of the genera subsets. The first ones were defined as the genera with abundance and frequency $\geq 70 \%$ within one of the groups found in the total NMDS. The second ones were $\geq 60 \%$ in all the samples and the third ones were $\leq 30 \%$ in all the samples.

\section{Taxonomic aggregation}

The abundance data of genera were aggregated to the levels of family, order, class and phylum. Furthermore, they was evaluated in different transformations; due to the fact that temporal signals may be masked more by some transformations than by others (Somerfield and Clarke, 1995; Olsgard et al., 1997, 1998; Clarke and Warwick, 2001). Twentyfive ranked matrices of similarities were constructed using the Bray-Curtis similarity measure: five matrices of taxonomic levels with five transformations for each one (untransformed data, square root, fourth root, $\log (x+1)$, and presence/absence). Each similarity matrix was compared to the others using the Spearman rank correlation, and the significance of the correlation was determined by a permutation procedure (Clarke and Warwick, 2001). A permutation procedure is essential here because of the lack of independence of elements in a similarity matrix (Somerfield and Clarke, 1995). Ordination analyses were accomplished by the use of NMDS.

\section{RESULTS}

The temporal pattern of the total community (337) is shown in Figure 2a. The composition and abundance of organisms in 1994 to 1996 (group A) are separated from those of later years (group B), suggesting a clear difference in abundance and composition (Table 1 and 2). The greatest abundances and number of genera correspond to group B (Table

TABLE 1. - Mean number of the taxonomic levels and abundance by groups formed in the total NMDS. The standard error is in parenthesis.

\begin{tabular}{lrr}
\hline & Group A & Group B \\
\hline Genera & $130(13.8)$ & $174(6.4)$ \\
Families & $78(7.4)$ & $90(6.4)$ \\
Orders & $29(2.0)$ & $31(0.7)$ \\
Classes & $8(1.0)$ & $7(0.0)$ \\
Phyla & $6(0.0)$ & $5(0.0)$ \\
Abundance (organisms* ${ }^{-2}$ ) & $1198(346)$ & $2633(467)$ \\
\hline
\end{tabular}



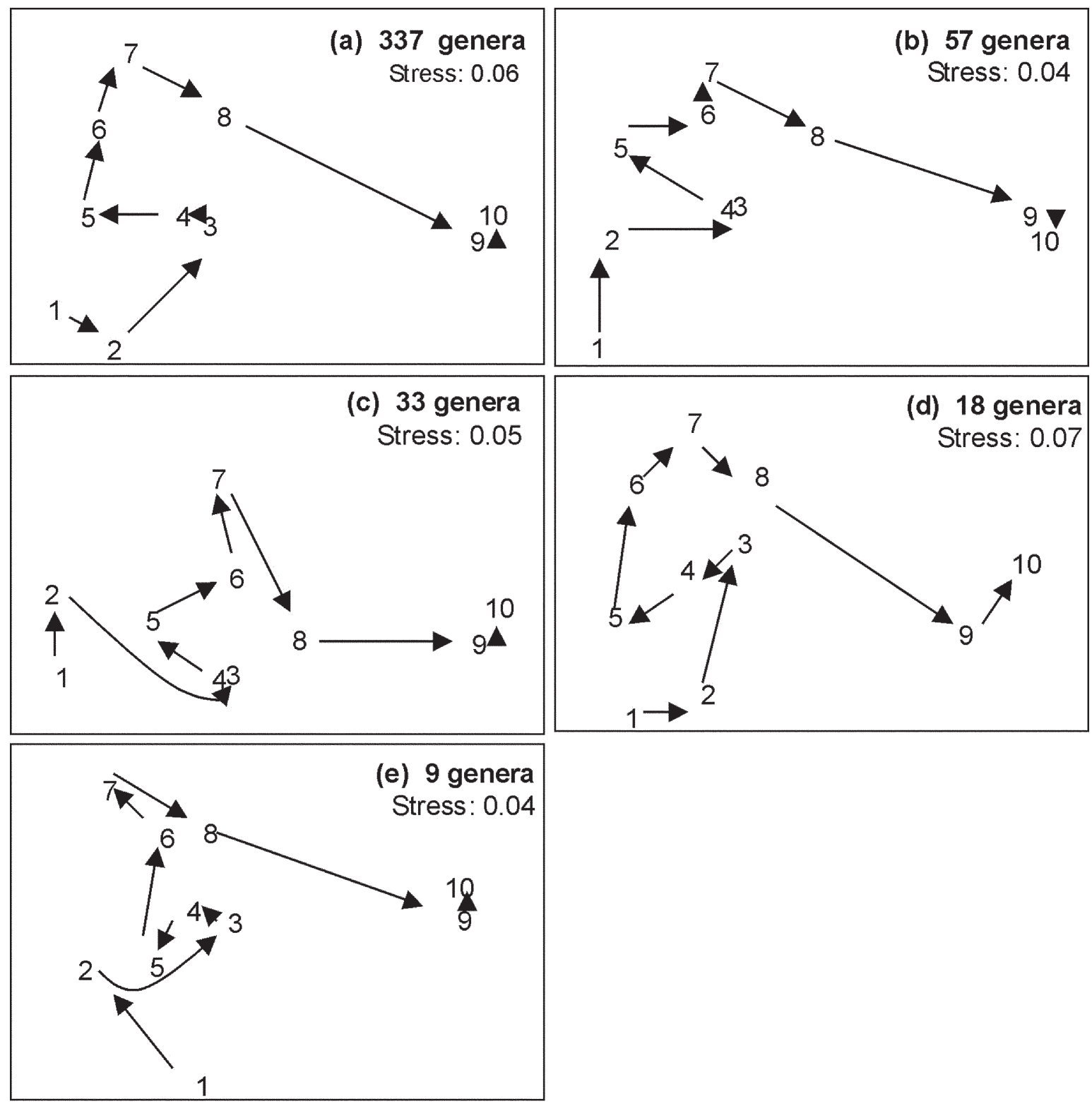

FIG. 2. - NMDS analysis of $\log (\mathrm{x}+1)$ transformed abundances and Bray-Curtis similarities. (a) total genera 337, (b)-(f) genera subset originated by stepwise procedure showing high level of matching (rho) with full data. Arrows follow chronological order: (1) Dec-94, (2) Mar-95, (3) Jun-95, (4) Sep-95, (5) Dec-95, (6) Apr-96, (7) Jul-96, (8) Nov-96, (9) Oct-01, (10) Jun-02. Group A formed by 1-8 and group B by 9-10.

1). Group A has 17 characteristic genera, whereas group B has 75 (Table 2), representing $28 \%$ of the total abundance. The percentage of characteristic polychaetes, sipunculids, molluscs, and echinoderms in group 2001-2002 (B) compared to group 1994-1996 (A) increased, while that of characteristic crustaceans and bryozoans decreased.

Four temporal ordinations formed by subsets of 57, 33, 18 and 9 genera show a high correlation with the fixed or total matrix (337 genera) (Fig. 2 b-e; Table 3). There are other subsets of genera that reproduce information contained in the total analysis. Consequently, similar results may be obtained whether all the genera or a small group is analysed. Most genera were common in samplings and characteristic of one of the two groups observed in the ordination (Table 3). They 'explain' the multivariate temporal pattern that was found. Thus, these assemblages presented several structurally redundant subsets of genera, many of which are polychaete worms.

A similar map of the ordination is obtained by analysing only the information from polychaetes and comparing it with that of all the genera, although this is slightly compressed on the vertical axis because several of the dominant genera in sam- 
TABLE 2. - Characteristic genera for each group formed according to total NMDS, i.e. abundance and frequency $\geq 70 \%$ within the group.

Group A

Hypaniola, Onuphis

Listriella, Ophelina,

Ceratocephale.

Cupuladria,

Cheramus,

Praxillella,

Speocarcinus,

Pinnixa,

Eudevenopus,

Alpheus,

Sphaerosyllis,

Parandalia,

Euniphysa,

Antalis,

cf. Pseudoleiocapitella
Group B

TABLE 3. - Relationship between selected genera subset and total data, based on similarity matrices derived from log $(X+1)$ transformed abundances. rho, the Spearman rank correlation; p, probability level. Characteristic, frequent and rare genera are defined in the methodology.

\begin{tabular}{|c|c|c|c|c|c|c|c|}
\hline & \multirow[t]{2}{*}{ Subset } & \multirow[t]{2}{*}{ rho } & \multirow[t]{2}{*}{$\mathrm{p}$} & \multicolumn{2}{|c|}{ Characteristic $(\%)$} & \multirow{2}{*}{$\begin{array}{l}\text { Frequent } \\
(\%)\end{array}$} & \multirow{2}{*}{$\begin{array}{c}\text { Rare } \\
(\%)\end{array}$} \\
\hline & & & & Group A & Group B & & \\
\hline Total data & 337 & - & - & 5.0 & 22.8 & 16.3 & 33.2 \\
\hline Genera & 57 & 0.95 & $<0.001$ & 5.3 & 38.6 & 22.8 & 19.3 \\
\hline Genera & 33 & 0.95 & $<0.001$ & 15.2 & 36.4 & 27.3 & 9.1 \\
\hline Genera & 18 & 0.95 & $<0.001$ & 5.6 & 11.1 & 44.4 & 11.1 \\
\hline Genera & 9 & 0.95 & $<0.001$ & 11.1 & 66.7 & 11.1 & 11.1 \\
\hline Polychaetes & 152 & 0.94 & $<0.001$ & 6.0 & 31.8 & 25.8 & 17.2 \\
\hline Polychaetes & 93 & 0.96 & $<0.001$ & 9.7 & 31.2 & 26.9 & 12.9 \\
\hline Polychaetes & 11 & 0.95 & $<0.001$ & 18.2 & 72.7 & 0.0 & 0.0 \\
\hline Genera $(>1 \%)$ & 59 & 0.96 & $<0.001$ & 13.6 & 40.7 & 44.1 & 1.7 \\
\hline Genera $(>2 \%)$ & 27 & 0.88 & $<0.001$ & 14.8 & 29.6 & 51.9 & 0.0 \\
\hline Crustaceans & 104 & 0.82 & $<0.001$ & 5.8 & 9.6 & 8.7 & 42.3 \\
\hline Molluscs & 66 & 0.57 & $<0.002$ & 1.5 & 21.5 & 7.7 & 46.2 \\
\hline Echinoderms & 11 & 0.19 & $<0.170$ & 0.0 & 18.2 & 18.2 & 54.5 \\
\hline Sipunculids & 4 & 0.68 & $<0.004$ & 0.0 & 0.0 & 75.0 & 25.0 \\
\hline
\end{tabular}

plings 1-8 belong to non-polychaete groups of organisms like amphipods Ampelisca and Listriella (Fig. 3b). The similarity matrix for all polychaetes shows a 0.94 correlation with all the genera (Table 3). Extracting a minor group of polychaete genera, the temporal pattern becomes more similar to total genera (Fig. 3c-d). Eleven polychaete genera show a similar pattern to that obtained by analysing the entire assemblage and all are characteristic genera (Table 3).

Genera subsets formed by other groups (crustaceans, molluscs, echinoderms or sipunculids), show a lesser correlation with total genera, due to the fact that rare genera increase, while characteristic and common genera decrease (Table 3). On the other hand, group 1994-1996 (A) of echinoderms and sipunculids has no characteristic genera.

In the total NMDS analysis there is a higher percentage of rare genera (33.2\%) compared to frequent genera $(16.3 \%)$. The temporal pattern is preserved as the number of rare genera decreases, while the percentage of frequent and characteristic genera increases (Table 3 ). Figure $4 \mathrm{~b}$ shows the analysis of the set of dominant and frequent genera, where those comprising $1 \%$ or more of total abundance were selected. This percentage retains the two conditions of abundance and frequency. The similarity matrix for these characteristic genera shows a high correlation with the total community and maintains the temporal pattern. Percentages above $2 \%$ include more dominant genera in comparison to characteristic genera, the correlation decreases and the temporal pattern becomes distorted (Fig. 4c, Table 3).

NMDS ordinations of abundance data indicate that as abundances are aggregated to the family taxonomic level the temporal pattern of assemblage is retained. However, further aggregation begins to alter the perceived temporal pattern (Fig. 5). The plots have low stress values, reflecting that the NMDS preserves inter-sample relationships in a two-dimensional plot. The results of tests for differences between similarity matrices show that the 

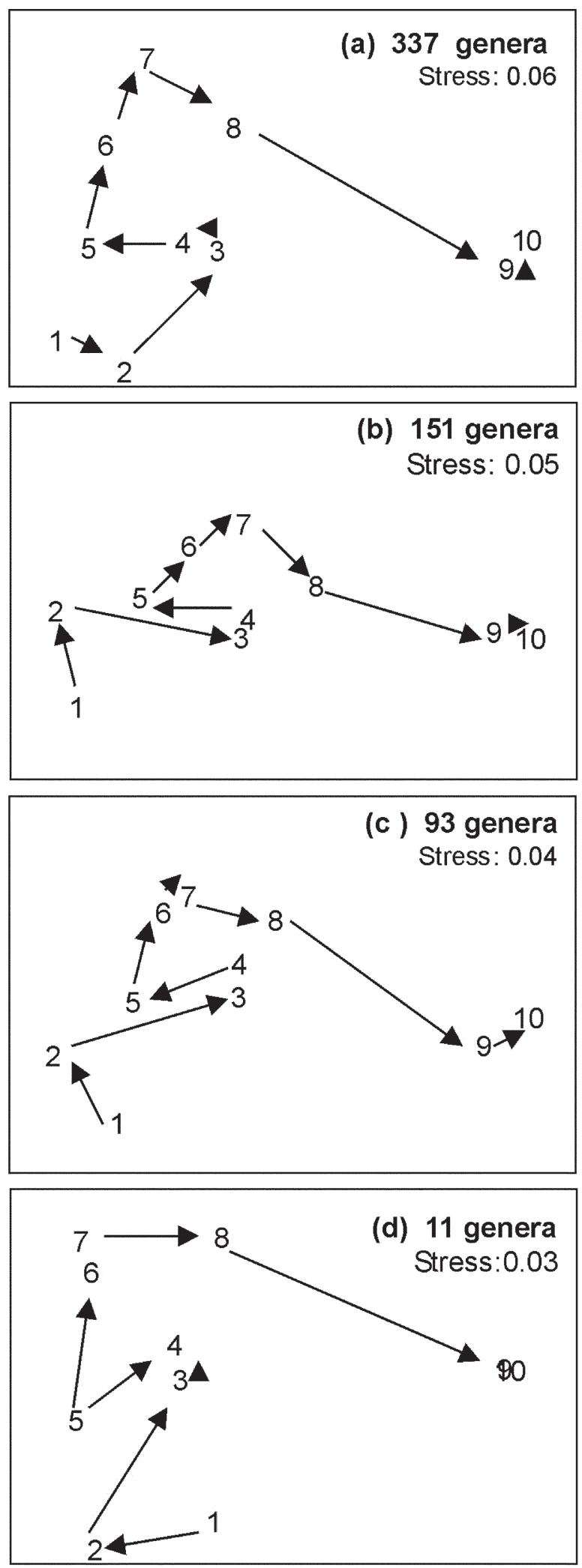

FIG. 3. - NMDS analysis of $\log (x+1)$ transformed abundances and Bray-Curtis similarities. (a) Total genera 337, (b) total polychaete genera 151, (b)-(c) series of subsets of polychaete genera showing high level of matching (rho) with total data. Numbers as in Fig. 2.
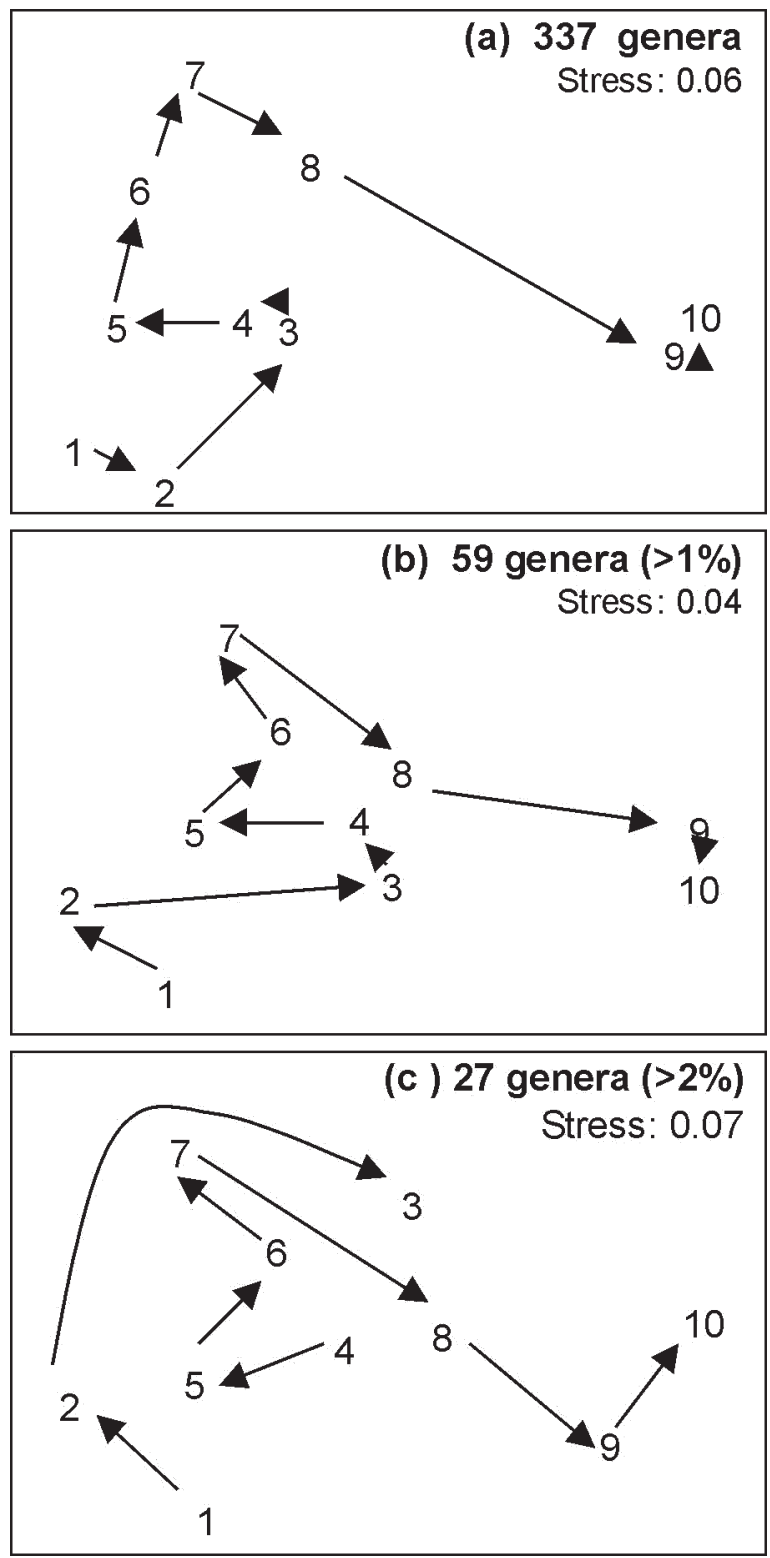

FIG. 4. - NMDS analysis of $\log (\mathrm{x}+1)$ transformed dominant genera and Bray-Curtis similarities. (a) total genera 337, (b) $\geq 1 \%, 59$ genera (c) abundance $\geq 2 \%, 27$ genera. Numbers as in Fig. 2 .

matrices are highly correlated at all taxonomic levels, and they are highly significant (Table 4). The correlations decrease as the taxonomic levels increase; for example, families are more highly correlated with genera than orders, classes or phyla. The relationships between matrices derived from presence/absence transformation of abundances are not as clear, and the temporal pattern changes to aggregate at higher taxonomic levels than genus. Presence/absence transformation emphasises the contributions of rare taxa. In other cases, aggregation of genus to family level is not affected by the data transformation used; for example, as the contri- 
TABLE 4. - Pair-wise Spearman rank correlations between similarity matrices derived from genera abundance data, aggregated to higher taxonomic levels and using different transformations. The majority of correlations are significantly different from zero, by a permutation test, at $\mathrm{p}<0.001$; exceptions $* \mathrm{p}<0.002 ; * * \mathrm{p}<0.005$ and $* * * \mathrm{p}<0.016$. The columns correspond to the taxonomic level and the rows to the transformations used.

\begin{tabular}{lllll}
\hline & Family & Order & Class & Phylum \\
\hline non transformed genera & 0.982 & 0.945 & 0.911 & 0.910 \\
square root genera & 0.931 & 0.870 & 0.889 & 0.858 \\
fourth root genera & 0.862 & 0.810 & 0.864 & 0.811 \\
log (X + 1) genera & 0.922 & 0.861 & 0.888 & 0.833 \\
presence/absence genera & 0.749 & $0.534 *$ & $0.566 * *$ & $0.538 * *$ \\
& & & & \\
\hline
\end{tabular}

butions of abundant, or combinations of abundant and intermediate taxa are emphasised, the temporal pattern of assemblage is similar (Fig. 5). The square root and $\log (x+1)$ transformations downplay the taxa dominants; these transformations have a similar temporal pattern and coefficient of correlation in the different taxonomic levels, so $\log (x+1)$ is chosen for these data.

This study contributed to the knowledge of diversity in the region, increasing the number of list- ed genera registered, especially polychaetes, peracarids and sipunculids.

\section{DISCUSSION}

Different ordinations of subsets of genera closely match the total community pattern, showing that the structural redundancy is high, so a significant amount of genera characterise community composition. Clarke and Warwick (1998) argued that those groups of taxa containing 'response units' (i.e. those responding similarly to total fauna) appear to be functionally equivalent to another 'response unit', and these units seem to respond in a similar way to environmental changes. In this study assemblage, these 'response units' comprised subsets of the same or different taxonomic groups. One of these was entirely composed of polychaetes; hence, they emerge as an alternative to be used in temporal analyses in these sublittoral areas, to avoid dependence upon analysis of the total fauna. Subsets of crustaceans, molluscs, echinoderms and sipunculids

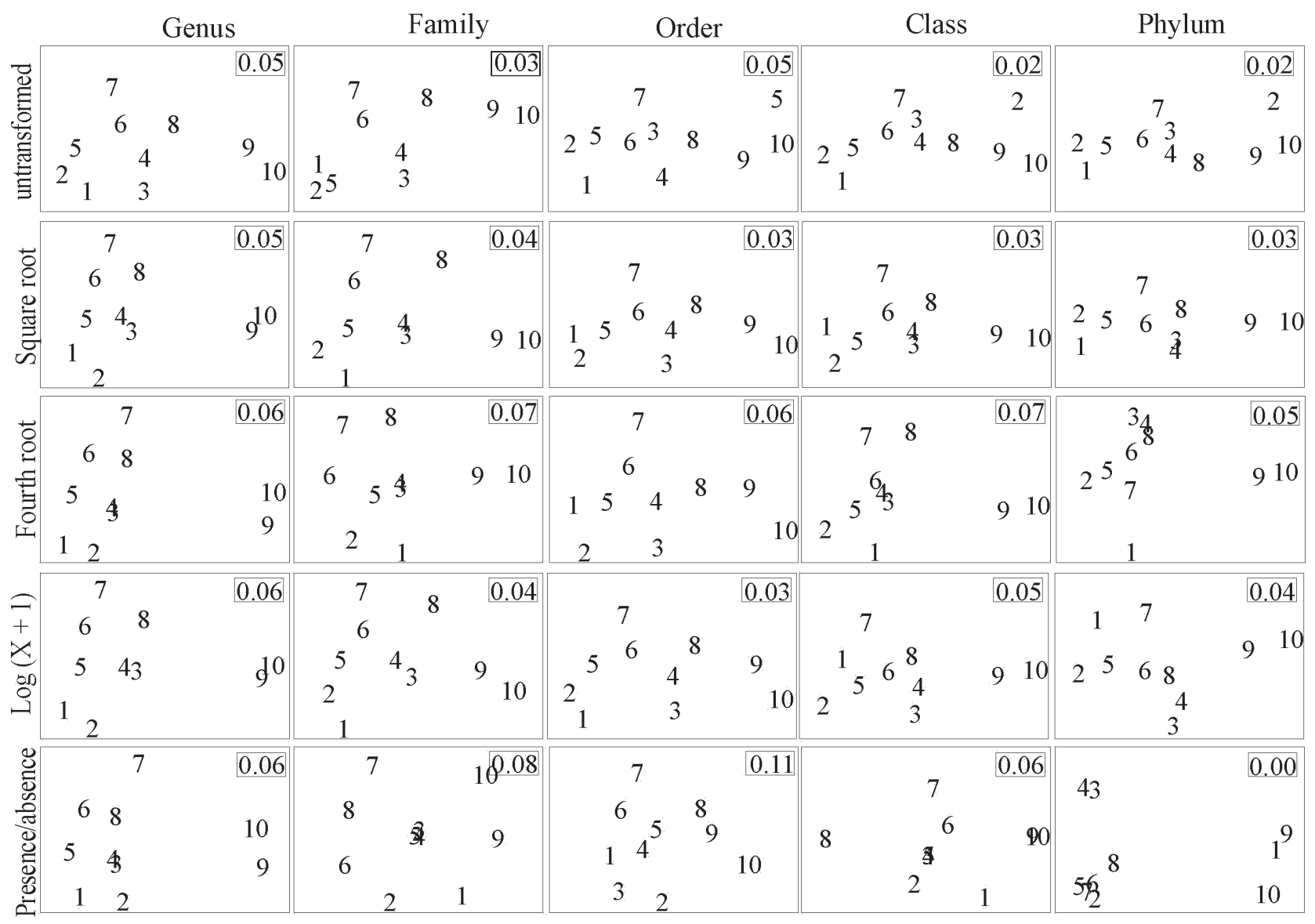

FIG. 5. - NMDS ordinations using similarity matrices derived from non-transformed, square root, fourth root, log $(x+1)$, presence/absence abundances of genera, families, orders, classes and phyla. Stress values on top right of plots. Numbers as in Fig. 2. 
respond differently to total fauna. The polychaetes are an abundant, diverse and widely distributed group on soft bottoms, but are a poorly studied group for this area. The polychaete species recorded within the southern Caribbean represent $20 \%$ of the total found throughout the Caribbean. Joint efforts of investigators are required in order to develop a better understanding of polychaete taxonomy in the region.

Another alternative 'response unit' may be the dominant and common or characteristic genera of the assemblage. The contributions of dominant taxa show that family taxonomic level is sufficient to describe temporal changes. However, this depends on the spatial and temporal scale that is used, a fact that must be considered before it is used to analyse temporal changes.

The studied community contains several structurally redundant subsets of genera. One way of taking advantage of this redundancy is aggregation to higher taxonomic levels. The results show that on the analysed temporal and spatial scale the pattern is maintained as data are aggregated to families, but at higher levels this pattern starts to disappear.

On the other hand, as the contributions of common or combinations of common and intermediate taxa are emphasised in these assemblages, differences between analyses of genera abundance and analyses of family abundance are not apparent. However, emphasising the contributions of rare taxa differences are notable, temporal pattern changes as taxonomic levels increase. The relative importance of taxa (or transformation) determines the aspect of the assemblage that is emphasised in subsequent analyses and can affect the outcome of multivariate analyses, particularly as data are aggregated to a higher taxonomic level (Olsgard et al., 1998). In these assemblages, taxonomic level to a higher order changes the outcome of the multivariate temporal pattern as different aspects of the assemblage are examined.

In temperate zones it has been concluded that, in pollution gradients, faunal patterns may be disclosed by using higher taxonomic level abundances as high as class and phylum (Ferraro and Cole, 1990; Warwick et al., 1990; Somerfield and Clark, 1995; Vanderklift et al., 1996; Olsgard et al., 1997, 1998). However, in areas where there is no contamination, correlations to class or phylum decrease to values below 0.70 . Consequently, analyses at class or phylum level must be avoided in areas with weak gradients in faunal composition (Vanderklift et al., 1996;
Olsgard et al., 1998). In this study, higher correlations than 0.70 were found between class or phylum matrices, which would indicate a stronger gradient in faunal composition, but not strong enough to disclose the same patterns at taxonomic levels as high as class or phylum. The temporal change pattern found is more related to natural disturbances (e.g. La Niña in 1999) than to a pollution gradient. In a natural variation gradient on the coast of New South Wales, Australia, the results were similar to those shown here: aggregation to family showed very little loss of information for the description of spatial natural variation in macrofauna (James et al., 1995). These results have general significance in that they support accumulating evidence indicating that taxonomic sufficiency is a useful concept in unpolluted areas too.

Recently, the evaluation of diversity patterns has received increasing interest due to the rapid deterioration and loss of marine ecosystems, especially in coastal areas (Bolger, 2001; Ellingsen, 2001). Although it seems contradictory to use abundance of organisms at levels higher than species to study biodiversity patterns, comparisons between areas with few or no species in common makes it necessary to use higher taxonomic levels (Olsgard et al., 1998). This study uses abundances of organisms at the genus level, which is important to highlight the diversity of the region. There is also the practical matter of the precision and accuracy of taxonomic identification (Ellis, 1985). Species identification is more error-prone than identification to higher taxa. This error increases where taxonomic literacy and expertise is lacking, as in the southern Caribbean. The correct identification to a higher taxon may be preferable, both biologically and statistically, than incorrect identification to species (Ferraro and Cole, 1990). Taxonomic sufficiency is a pragmatic concept in which the accuracy of identification is balanced against the need for information (Ellis, 1985).

In conservation studies, recent analyses confirm that urgent attempts to catalogue the distribution of biological diversity may be facilitated by focusing at the level of genera or families rather than species (Andersen, 1995; Balmford et al., 1996). However, other authors believe that the approximations must not be made before one acquires a profound knowledge of systems and their species (Terlizzi et al., 2003), and that pretending to perform conservation studies without considering species is contradictory (Maurer, 2000). The last two points are difficult to 
achieve, due to the lack of taxonomic expertise for many groups. Developing a detailed knowledge of the biodiversity in the southern Caribbean may take a long time, because there are simply not enough people who can confidently and correctly identify to the species level difficult groups such as polychaete worms, peracarid Crustacea or sipunculids. Also, sufficient funds are not currently available to train taxonomists and systematists. It is necessary to conduct joint efforts in order to increase the availability of taxonomic expertise. Meanwhile, it is important to begin developing ecological studies that describe the spatial and temporal patterns of the assemblages, taking advantage of the taxonomic sufficiency and structural redundancy; but keeping in mind its limitations due to the lack of comprehensive ecological information (Maurer, 2000; Terlizzi et al., 2003).

Taxonomic sufficiency and structural redundancy are alternatives that help to avoid the taxonomic problems of the region. However, before making any general recommendations for the tropics it is important to increase studies in other areas.

In conclusion, there is a high degree of structural redundancy exhibited by a large number of characteristic, common and dominant genera. It was also possible to detect a temporal change in the structure of the assemblage by using the polychaete group. Therefore, as the contributions of common or combinations of common and intermediate taxa are emphasised, the aggregation to family level preserves the temporal pattern found at the genus level, but aggregations above this level distort it. The results are important for describing community patterns in these tropical communities, given that serious difficulties exist in identifying some organisms.

\section{ACKNOWLEDGEMENTS}

This paper is part of the first author's doctoral thesis (Departamento de Oceanografía, Universidad de Concepción, Chile). Sincere thanks are extended to the Graduate School and German Academic Exchange Service (DAAD) for providing scholarships. The work was funded by the Instituto de Investigaciones Marinas y Costeras INVEMAR and the Empresa Colombiana de Petróleos ECOPETROL - Santa Marta, Colombia. Two anonymous reviewers made helpful comments on the manuscript. We thank Jeffrey M. Clayton, Claudia Arango and Patricia Lattig for improving the English.

\section{REFERENCES}

Agard, J.B.R., J. Gobin and R.M. Warwick. - 1993. Analysis of marine macrobenthic community structure in relation to pollution, natural oil seepage and seasonal disturbance in a tropical environment (Trinidad, West Indies). Mar. Ecol. Prog. Ser., 92: 233-243.

Andersen, A. - 1995. Measuring more of biodiversity: genus richness as a surrogate for species richness in Australian ant faunas. Biol. Conserv., 73: 39-43.

Balmford, A., A.H. Jayasuriya and M.J. Green. - 1996. Using higher-taxon richness as a surrogate for species richness: II Local applications. Proc. R. Soc. Lond. B., 263: 1571-1575.

Bolger, T. -2001 . The functional value of species biodiversity - a review. Biol. Env., 101B: 199-224.

Clarke, K.R. and R.M. Warwick. - 1998. Quantifying structural redundancy in ecological communities. Oecologia, 113: 278289.

Clarke, K.R. and R.M. Warwick. - 2001. Change in marine communities: an approach to statistical analysis and interpretation. Second edition, PRIMER-E: Plymouth, UK.

Ellingsen, K.E. - 2001. Biodiversity of a continental shelf soft-sediment macrobenthos community. Mar. Ecol. Prog. Ser., 218: 1-15.

Ellis, D. - 1985. Taxonomic sufficiency in pollution assessment. Mar. Pollut. Bull., 16: 459.

Ferraro, S.P. and F.A. Cole. - 1990. Taxonomic level and sample size sufficient for assessing pollution impacts on the Southern California Bight macrobenthos. Mar. Ecol. Prog. Ser., 67: 251-262.

Gray, J.S. - 2002. Species richness of marine soft sediments. Mar. Ecol. Prog. Ser., 244: 285-297.

Guzmán, A. and C.B. García. - 1996. Taxonomic aggregation and the detection of patterns in a tropical marine benthos data set. Rev. Biol. Trop., 44: 907-910.

Hanski, L. - 1997. Be diverse, be predictable. Nature, 390: 440-441.

James, R.J., M.P. Lincoln and P.G. Fairweather. - 1995. Sieve mesh-size and taxonomic resolution needed to describe natural spatial variation of marine macrofauna. Mar. Ecol. Prog. Ser., 118: $187-198$.

Maurer, D. - 2000. The dark side of taxonomic sufficiency (TS). Mar. Pollut. Bull., 40: 98-101.

McGrady-Steed, J., P.M. Harris and P.J. Morin. - 1997. Biodiversity regulates ecosystem predictability. Nature, 390: 162-164.

Naeem, S. and S. Li. - 1997. Biodiversity enhances ecosystem reliability. Nature, 390: 507-509.

Olsgard, F., P.J. Somerfield and M.R. Carr. - 1997. Relationships between taxonomic resolution and data transformations in analyses of a macrobenthic community along an established polluted gradient. Mar. Ecol. Prog. Ser., 149: 173-181.

Olsgard, F., P.J. Somerfield and M.R. Carr. - 1998. Relationships between taxonomic resolution, macrobenthic community patterns and disturbance. Mar. Ecol. Prog. Ser., 172: 25-36.

Snelgrove, P., T.H. Blackburn, P.A. Hutchings, D.M. Alongi, J.S. Grassle, H. Hummel, G. King, I. Koike, P.D.J. Lambshead, N.B. Ramsing and V. Solis-Weiss. - 1997. The importance of marine sediment biodiversity in ecosystem processes. Ambio, 26: $578-583$.

Somerfield, P.J. and K.R. Clarke. - 1995. Taxonomic levels, in marine communities studies, revisited. Mar. Ecol. Prog. Ser., 127: 113-119.

Terlizzi, A., B. Bevilacqua, S. Fraschetti and F. Boero. - 2003. Taxonomic sufficiency and the increasing insufficiency of taxonomic expertise. Mar. Pollut. Bull., 46: 556-561.

Vanderklift, M.A., T.J. Ward and C.A. Jacoby. - 1996. Effect of reducing taxonomic resolution on ordinations to detect pollution-induced gradients in macrobenthic infaunal assemblages. Mar. Ecol. Prog. Ser., 136: 137-145.

Walker, B. - 1992. Biodiversity and ecological redundancy. Conserv. Biol., 6: 18-23.

Warwick, R.M. - 1988. Analysis of community attributes of the macrobenthos of Frierfjord/Langesundfjord at taxonomic levels higher than species. Mar. Ecol. Prog. Ser., 46: 167-170.

Warwick, R.M., H.M. Plat, K.R. Clarke, J. Agard and J. Gobin. 1990. Analysis of macrobenthic and meiobenthic community structure in relation to pollution and disturbance in Hamilton Harbour, Bermuda. J. Exp. Mar. Biol. Ecol., 138: 119-142.

Scient. ed.: W. Norbis 
